General and Applied Chemistry

A Brief College Course. By Prof. Arnold J. Currier and Prof. Arthur Rose. (International Chemical Series.) Pp. ix +275 . (New York and London: McGraw-Hill Book Co., Inc., 1948.) $18 s$.

7 HIS boolgfords a one-year course in chemistry for stuglnts whose main subject is agriculture, enginering or other applied science. Its aim is to help the study of these subjects by giving a knowledge of materials. Obviously such a course must cove much of the usual ground of introductory chemistry. Actually the subject-matter is approximately the ehemistry required for matriculation, with the addition of two chapters on carbon compounds. Questions and exercises are within, and reading references at the end of, each chapter. There are an appendix of useful tables and an index. Theory is not unduly stressed, the main emphasis being on the everyday application of materials. This feature is thoroughly well done. The only notable omissions are some account (rather than a mention) of adsorption and the colloidal state, and some discussion of the handling of materials and of the hazard of their indiscriminate mixing.

Its numbered paragraphs, its interesting tables, its clear and simple exposition of principles and concepts, make this book most suitable for the class of students for whom it was written.

G. F.

\section{General Chemistry for Colleges}

By Alexander Smith. Sixth edition, by Prof. William F. Ehret. Pp. xiii +677. (New York: D. AppletonCentury Co., Inc.; London: G. Bell and Sons, Ltd., 1946.) 20s. net.

GIRST puleshed in 1906, hitherto kept up to date 1 by Prof Kendall, this book, embodying Smith's disting 6 presentation of the subject, has profoundly influenced the teaching of chemistry. The prenent editor is to be congratulated on retaining the solid framework of the original "Smith", while making what is practically a new book. The size of the page has been increased so that it now measures $9 \frac{1}{2}$ in. $\times 6 \frac{1}{2}$ in., permitting of the use of large and striking illustrations; and Prof. W. F. Ehret has revised and added to the reading references, and has thoroughly overhauled the sets of questions. However, his greatest innovation is his treatment of the theoretical matter, most of which he has rewritten. Atomic architecture now occurs earlier in the book, so that structure can be related to properties. Indeed, all the newer physical concepts which throw such light on structure and behaviour are clearly and simply expounded. Terms not yet in general use, such as 'oxidation numbers', and Brönsted's definition of acids, are explained and temperately discussed. This revision, so thoroughly and ably done, will ensure "Alexander Smith" retaining its place in the first clags of chemistry texts.

G. F.

Worked Examples in Chemistry

By H. P. Starck. Pp. 176. (London: Hutchinson's Scientific and Technical Publications, n.d.) 12s. $6 d$. net.

THE 156) Brked examples which make this book are mastly taken from recent papers set at InterScience, Ofirst M.B., National Certificate, Higher Sahoo and similar examinations. The problems are not fimited to elementary work and to the calculations of ahalysis, but illustrate a variety of subjects such as the partition coefficient, the eutectic point, osmotic pressure and related phenomena, electrolysis and electrode potentials. The author has classified the examples, grouped them into chapters of increasing difficulty, and whenever necessary added theoretical matter to make clearer an understanding of the principles involved. Much experience in a technical college has thoroughly acquainted him with the difficulties of students, so we find these illustrative examples clearly set out in simple steps, and, so far as we have checked, accurately solved. To the serious student and to teachers not too strong in this section of chemistry, the book should be of great value.

Our Enemy the Termite

$416^{\mathrm{G} . \mathrm{F}}$.

By Thomas Elliott Snyder Revised edition. Pp. xiii + 257. (Ithaca, N.Y Comstock Publishing Co., Inc.; London : Cppifto and Co., Ltd., 1948.) $20 s$. net.

THE gerpral orm and purpose of this book, the first edition of which was published in 1935 , remains unchanged-to provide a popular but acch are work on termites and their control. Progress in knowledge has necessitated the revision of some sections and the complete rewriting of others. This applies to the accounts of biology, nutrition, caste determination and reproduction, and to the description of recent advances in termite control.

Taking the world as a whole, mankind suffers more economic loss from the termites than from any other group of insects. But while the author, who is not only an authority but also an enthusiast on termites, is intent on stressing the importance of his group, he is at great pains to counter the exaggerated fears fostered by the unscrupulous termite-control agencies -almost as great a pest in the United States, it would appear, as the termite itself. In the National Pest Control Association reputable commercial firms and authorities on termites have co-operated in the formulation of control procedures and the development of ' $a$ code of ethics'. The recommendations of the Association are printed in full. They consist almost wholly of prevention by proper building construction (with provisions written into city building-codes if possible) and cure by structural modifications. Chemical treatment for controlling established infestations occupies a secondary place. The book deals primarily with termites of the United States; keys to the genera of these are included, based on winged adults, soldiers and habits.

How to Live with a Dog

By C. L. B. Hubbard. Pp. 75. (London: Feature Books, Ltd., 19\%8) $3 s$. net.

DOG books gre usually addressed to professional and pour dog-breeders and exhibitors, and the owne of ordinary house-dogs are often left to grappl with academic works or pick up their informatop by hearsay. Mr. C. L. B. Hubbard has tried to help those who wish to make a success of their dog-keeping, and in this little book has condensed much useful information on house-dog management into small compass and plain words. Advice is given on the physical characteristics of dogs, the various breeds, their peculiar behaviour characteristics, their training and grooming, and the way in which they should be fed both in times of plenty and at present.

Mr. Hubbard writes with considerable enthusiasm, and although he attributes to dogs characteristics which are not apparent to everyone, they add to the interest of a book which will be useful to dog lovers. T. H. H. 